the fact that the only works that are retranslated are those which have entered the canon in the new system, and this new status gives the translator greater leeway with the specific conventions of the target literary system in a situation in which the nature of the recognized "work of art" acquires greater importance. In fact, on the back cover there is a statement which expands on something said by the translator in his introduction: "The novelty and interest of this BILINGUAL ANTHOLOGY ... rests on the fact that for the first time we are offered a Spanish translation of Whitman's poems in their first versions, in which the urge that brought them into being manifests itself much more faithfully than do the final ones, expurgated by the poet himself." Thus, the idea of "fidelity" prevails in the translator's intention to such an extent that, in a very unusual but significant move, it is claimed that the source text chosen in this case is the most faithful to the "spirit" of the writer-curiously enough, actually against his will, because Whitman asked to be published always in the last version to be revised by himself, i.e. what is commonly known as the deathbed edition. The claim that this edition is the most faithful is also extremely revealing as to the prerogatives of every translation, which in the act of interpretation establishes its own source text. In this case, the situation is made much clearer by the two facts that the translator has had to choose among several possible source texts, and that he has sifted even that version and kept only a part of itpressumably what he sees as the most genuine part.

In short, we have here a new Spanish version of Leaves of Grass whose main innovation lies in the fact that it presents the poems in a version, the first one, scarcely known in the English-speaking countries and completely unknown in the Spanish literary system. This is, undoubtedly, a new contribution that should be welcomed. From a stylistic point of view, Villar Raso's translation is what has been termed a translation of poetry, i.e. an auxiliary version. Its formal ambitions are therefore limited, though it shows a clear concern for correctness and it pays special attention to linguistic tenor, much in line with this type of translations, which on the semantic level stay very close to the original at the same time as they respect target language usage.

Javier Franco Aixelá

William Shakespeare. Titus Andronicus. Ed. Jonathan Bate. The Third Edition of the Arden Shakespeare. London: Routledge, 1995 - William Shakespeare. Antony and Cleopatra. Ed. John Wilders. The Third Edition of the Arden Shakespeare. London: Routledge, 1995 - William Shakespeare. King Henry V. Ed. T. W. Craik. The Third Edition of the Arden Shakespeare. London: Routledge, 1995.

We welcome the publication of Titus Andronicus (edited by Jonathan Bate), Antony and Cleopatra (edited by John Wilders) and King Henry V (edited by T. W. Craik), the first three plays to appear in the third edition with a new concept of editorial work. The Arden Shakespeare has been a landmark in textual analysis and critical research for nearly one hundred years. It has been the origin of a textual revolution in the editing of Shakespeare plays and has been particularly productive in the last decades of this century. The new 
series retains its pioneering spirit and presents a challenge to other Shakespearean critical editions for it sets out to find new ways of making Shakespeare meaningful to a new generation. Its contemporary concerns and detailed account of facts and problems related to Shakespearean criticism and theatrical production of the plays gives it a greater critical value.

Editions can be measured by their aims which, in this case, may be summed up by the insistence "upon the highest standards of scholarship and upon attractive and accessible presentation." "Textuality" and "theatricality" are to be considered the outstanding features of the new Arden. The text is the nodal point of the whole critical process. The edition is based on reliable texts and edited from the original quarto and folio but presented in a modernised version with a textual apparatus full of commentaries and notes. They explain verbal difficulties as well as the different interpretations given by editors, critics and performers to the Shakespearean plays in order to make possible a wider variety of critical approaches.

The edition uses a threefold structure. The text itself is followed by the commentary and textual notes. The traditional division into acts and scenes is preserved but has less prominence than it used to since it is of secondary importance bearing in mind the original shape of the Shakespearean text. It is preceded by an introduction which contains not only the traditional sections devoted to text, date of composition and dramatic sources, but also new ones such as the history of the critical and theatrical reception of the plays. The introduction also discusses the particular problems posed by them, for example a section is devoted to the question of the tragic in Antony and Cleopatra.

Plays are not only textual artifacts since they were written to be performed. The introduction and the commentary "are designed to present the plays as texts for performance." This is why their theatrical dimension is a major concern of the new Arden edition which offers a close reference to stage, film, and television versions where the dramatic text comes fully to life. So we get a balanced presentation of the Shakespearean text which cannot be reduced to mere textuality. Thus the introduction to Titus Andronicus opens with a reference to the theatrical conditions in Shakespeare's lifetime for they made possible the staging of Elizabethan plays, reflecting those special circumstances under which they were produced. Later we come across a section entitled "The Theatrical Life" where there is a detailed account of the staging from its first performances to the present day in order to give a comprehensive view of the theatrical potential contained in the text. The same applies to the edition of Henry $V$ in the section "Henry $V$ in Performance."

The Arden edition is also successful in the way it incorportes the trends of contemporary criticism emphasising the relevance of culture and history in the shaping of the text produced in a context to which it belongs and refers. The editors of the Arden Shakespeare are well aware, in the same way as cultural materialists would be, of the fact that plays are historical productions within a particular time and culture. The edition, therefore, tries to present each play as "shaped in history" since they have a historical dimension which limits and influences their textuality. Hence there is a positive consciousness of texts as historical products. It means that to come to terms with their sense, you need to be familiar with the context which creates them. 
The multidimensional critical effort made by the editors is to be valued for this new series is meant to provide an open forum for the discussion of contemporary critical issues about different aspects of Shakespearean studies which are analysed from a wide range of critical approaches and perspectives. So we have editors from both sides of the Atlantic with a comprehensive view of Shakespearean criticism. Moreover there is a strong feminist concern as a consequence of the relevance given to feminism in this series where there are more women editors than in previous editions. This is why we expect a positive feminist approach to some of the forthcoming texts, for example with the edition of Hamlet edited by Ann Thompson and Neil Taylor. This up-to-date critical insight makes the Arden contribution more valuable and more exciting.

The visual dimension of Shakespeare's drama is strongly stressed for the important role which it plays within the theatrical process. It means that performances in the theatre, and on film, and on television provide a new understanding of the plays. They contribute greatly to a deeper experience of the dramatic text which affects our imagination in many ways. The visual aspect is shown both in the relevance given to visual material where there are photographs and practical ideas, and in the presentation of the content and design, with new covers which have been redesigned. Therefore the reference to productions and interpretations challenges past editions and presents a new way of editing plays since they are regarded as theatrical texts. Discussion of dramatic aspects is also included to complete a view of the theatrical potential of the text.

Many reasons may be adduced to justify the appeal of the new edition which lies in the fact that quality has been matched with proven editorial success. The new Arden is Shakespearean in every sense even in its commitment to business, making the edition accessible to a great variety of readers for it contains not only scholarly but also informative material. Its general acceptance may be the greater because it also presents Shakespeare's complete works in single play editions.

However, an important question remains to be answered if the third series is going to be successful in the long run. Will it continue to set the standard for scholarly editions of Shakespeare's plays? The list of distinguished scholars who are going to contribute to the whole series seems to maintain our highest expectations. We can only say at the very outset of its publication that it is one of the finest critical editions of all time so far. And we very much hope that Arden's well that ends well.

José Manuel González Fernández de Sevilla

\section{John K. Eastman and Víctor M. Pina. Write Right. Alicante: Aguaclara, 1995, 205 pp.}

Over the last few years the ever-growing demand for EFL books for intermediate students has been complied with a wide range of reference grammars that have proved quite useful at different levels, both in secondary schools and language schools. Clear and comprehensive though these materials may be, the Spanish learner often feels that their treatment of some points is either over-theoretical or a little on the short side. They are 